Max-Planck-Institut für demografische Forschung

Max Planck Institute for Demographic Research

Konrad-Zuse-Strasse $1 \cdot$ D-18057 Rostock · GERMANY

Tel +49 (0) 3812081 - 0; Fax +49 (0) 3812081 - 202;

http://www.demogr.mpg.de

MPIDR WORKING PAPER WP 2007-035

NOVEMBER 2007

\title{
Do women with higher autonomy seek more maternal and child health-care? Evidence from Ethiopia and Eritrea
}

Gebremariam Woldemicael

(gebremariam.woldemicael@sociology.su.se)

This working paper has been approved for release by: Hill Kulu (kulu@demogr.mpg.de)

Deputy Head of the Laboratory of Contemporary European Fertility and Family Dynamics.

(C) Copyright is held by the authors.

Working papers of the Max Planck Institute for Demographic Research receive only limited review. Views or opinions expressed in working papers are attributable to the authors and do not necessarily reflect those of the Institute. 


\title{
Do Women with Higher Autonomy Seek More Maternal and Child Health-Care? Evidence from Ethiopia and Eritrea
}

\author{
Gebremariam Woldemicael $^{1}$
}

\begin{abstract}
Current research and policy on maternal and child health-care in Eritrea and Ethiopia focus primarily on female education and employment, while little attention is placed on women's decision-making autonomy. However, the role of women's decision-making in reproductive health cannot be overemphasized. In this paper, different dimensions of women's decision-making autonomy and their relationship to maternal and child health-care utilization are investigated using data from the Demographic and Health Surveys of Ethiopia and Eritrea. We simultaneously consider the role of socio-economic (indirect) indicators of women's status . The study shows that most autonomy indicators are important predictors of maternal and child health-care utilization although the strength and statistical significance vary by health-care utilization outcome and country, and in some cases significance is lost when socio-economic indicators are held constant. The strong positive effect of women's sole decision-making in visiting family or relatives on use of antenatal care and child immunization is particularly impressive. On the other hand, the loss of significance of other dimensions of women's decision-making when socio-economic factors are controlled for indicates that some health-care seeking behaviours are more dependent on socio-economic factors like education and employment. The results show that most socio-economic indicators have strong influence on both women's decision-making autonomy and on maternal and child health-care utilization. These findings suggest that both women's autonomy and socioeconomic indicators should be analyzed in order to derive a complete understanding of the determinants of maternal and child health-care utilization.
\end{abstract}

\footnotetext{
${ }^{1}$ Associate Professor, a research fellow at the Demography Unit/Sociology Department, Stockholm University, email: gebremariam.woldemicael@sociology.su.se or gebre_wm@yahoo.com
} 


\section{Introduction}

Recently, women's autonomy and its association with reproductive health and behaviour have emerged as a focal point of investigations and interventions around the world. Particularly, since the Cairo International Conference on Population and Development in 1994, ICPD (United Nations 1994), women's role has been a priority area not only for sustainable development, but also in reproductive health. At the ICPD, a general consensus was reached to ameliorate women's status, along with the related goals of improving women's reproductive health and securing their reproductive rights, which represents a paradigm shift that emphasizes the reproductive autonomy of individuals. Following the ICPD, there has been a number of recent studies that examine women's autonomy and its relationship with reproductive health and health outcomes (e.g., Kishor 2000, 2005; Bloom et al 2001; IUSSP 1997). Most of these studies found relationships between various aspects of autonomy and reproductive health and behaviour, but there are many complexities and contradictory findings among them, with different aspects of autonomy showing unexpected relationships with reproductive health and preferences in different settings and under different research designs. For example, lower fertility and fertility desire was observed among women with higher levels of autonomy in Bangladesh (Balk 1994) and in many regions of India (Jejeebhoy 1991), and lower fertility was found to be associated with women's greater autonomy in Malaysia, the Philippines, and Thailand (Tfaily 2004). These findings are attributed primarily to higher modern contraceptive use among women with higher autonomy (Schuler and Hashemi 1994; Dharmalingam and Morgan 1996; Morgan and Niraula 1995). On the other hand, in their study of autonomy of women and trends in fertility and contraceptive use in Egypt and Bangladesh Amin and Lloyd (1997) found that a low level of female autonomy was not a barrier to fertility change and contraceptive use in Egypt.

Very little empirical evidence is available about the relationship between women's status and maternal and child health utilization (Desai and Johnson 2005). A study in Uttar Pradesh in North India shows that women's autonomy is the major determinant of maternal health care utilization (Bloom et al 2001). These authors show that women with greater freedom of movement are more likely to receive antenatal care and to use delivery care and suggest that women's autonomy are equally important as 
educational and economic characteristics. Another study in India has shown that women who score greater autonomy are more likely to use antenatal and delivery care for their last birth than women with lower autonomy (Basu 1993). Women's reproductive health-seeking behaviour was found to be associated positively with freedom of movement and decision-making power in South India, but these effects were reduced when confounding factors were taken into account (Bhatia and Cleland 1995b). Using data from Zimbabawe, Zambia and Malawi, Hindin (2005) showed that women with lower autonomy in household decision-making were at an increased risk of having chronic energy deficiency in Zambia and Malawi, but not in Zimbabawe. A study by Kishor (2000) found women's autonomy to be an important explanatory factor in child survival and child health in Egypt net of other bio-demographic and socio-economic influences. Using DHS data from Zimbabwe, Becker (1997) examined the relationship between women's role in household decision-making and the extent of prenatal care and contraceptive use and found a strong association with prenatal care, but not with contraceptive use.

It is clear from the literature that the relationship between different aspects of women's autonomy and reproductive behaviour has not always been consistent across or within populations. Several factors may account for inconsistent relationships between women's autonomy and health or fertility outcomes. One fundamental problem that underlies the study of women's status and reproductive behaviour is how to adequately conceptualize women's autonomy. Women's autonomy is a complex and general term with many connotations that is influenced both by women's personal attributes and by the cultural norms of different groups (Makinwa and Jensen 1995). Such problems raise concerns about the definition and measurement of autonomy and have led many researchers to use indirect women's status indicators, such as educational attainment, employment, spousal age-difference, family type, etc. for women's decision-making autonomy in the analysis of reproductive behaviour (Jejeebhoy 1991). For instance, Safilos-Rothschild (1990) uses women's income as a key indicator of women's status to examine fertility in rural Kenya. Still others (e.g., Balk 1994; Tfaily 2004) have used both socio-economic factors and decision-making autonomy indicators and suggest that socio-economic indicators have direct effects as well. Yet critiques of available literature argue that women's socio-economic indicators such as education and employment are often not sensitive enough to 
capture the nuances of gender power relations and the ways in which they influence women's and men's reproductive behaviour (Presser and Sen 2000). It is argued that simply looking at schooling is not sufficient, but that the content of education, which often reinforces gender ideology, must be incorporated as well (Mason 1994). Similarly, women's employment does not automatically translate into women's control over their income. It is important to know who actually has access to and control over that income.

In this study, an attempt is made to move this research forwards using data from two East African countries, Eritrea and Ethiopia. Unlike many other previous studies, we examine different dimensions of women's autonomy and their relationship to maternal health-care seeking behaviour in relation to socio-economic factors. An important issue that we address is the relative importance of women's autonomy versus the socio-economic indicators on utilization of maternal and child health care. Although several studies have provided empirical evidence for these propositions in Asian countries, maternal health-care seeking behaviour has not been studied in relation to women's autonomy measures in Ethiopia and Eritrea. Understanding this relationship is particularly critical for these countries, which have been affected severely by conflict, civil war, and economic crisis and where gender disparity still is large. The findings of this study will have implications for health policies and programs in both countries and in East Africa in general.

In order to place the study in a broader context, first a brief background of the sociodemographic aspects of Eritrea and Ethiopia is given. Then, issues relevant to the concept of autonomy, the levels of women's autonomy in both countries, and the relationship between the autonomy indicators and socio-economic status indicators are discussed in that order. Finally, the paper examines whether direct measures of women's autonomy are important predictors of maternal and child health-care utilization in Ethiopia and Eritrea.

\section{Background to Ethiopia and Eritrea}

Eritrea and Ethiopia are among the least developed countries in the world with per

capita income of US\$190 and US\$110, respectively, as of 2004. The health-care 
system in both countries is underdeveloped, where about $70 \%$ of the populations suffer from some type of communicable disease and malnutrition. Maternal mortality ratio is still high in both countries, with about 670 deaths per 100,000 live births. The majority of women (94\% in Ethiopia and 73\% in Eritrea) deliver at home (CSA \& ORC Macro 2006; NSEO \& ORC Macro 2003). About 40\% of Eritrean children and $38 \%$ of Ethiopian children under five suffer from underweight. More than $76 \%$ of Ethiopian households and 60\% of Eritrean households have no access to safe drinking water and only one forth and one third of households in Ethiopia and Eritrea, respectively, have access to flush or pit toilet latrines (CSA \& ORC Macro 2006; NSEO \& ORC Macro 2003). About 39\% of males and 52\% of females in Eritrea have never attended school. The corresponding figures for Ethiopia are 52\% and 67\%. The male-female gap in education is more evident at higher than at lower levels of education.

As for the demographic situation, the two countries are still characterized by high fertility and mortality levels. This picture is typical of the situation in many countries in the East African region, but certain differences exist across countries. For example, total fertility (TFR) and infant mortality are currently lower in Eritrea, 4.8 children per woman and 48 per 1000 live births, respectively (NSEO and ORC Macro 2003), than in Ethiopia, where TFR and infant mortality are 5.4 children per woman and 80 per 1000 live births, respectively (CSA and ORC Macro 2006). In addition, while Ethiopia is the second-most populous African nation with about 75 million inhabitants (http://en.wikedia.org/wiki/Ethiopia), Eritrea has a population size of only about four million (Population Reference Bureau 2006).

Added to these situations, the two countries have been in a state of war with each other during the past three or more decades. The thirty-years war (1961-91) for Eritrea's independence and the 1998-2000 border conflict between the two countries coupled with recurrent drought have had significant political and economic impacts on both countries. Even though some progress has been made in socio-economic aspects like education and other sectors of the economy after 1991 the border conflict has seriously affected the gains achieved. For example, in Eritrea, the recent border conflict has resulted in a decline in real per capita GDP growth from about $+11 \%$ per year during $1993-97$ to $+3 \%$ in 1999 , and to $-10 \%$ in 2000 ; inflation rose from $17 \%$ in 
1998 to $27 \%$ in 2000 (GSE and UNICEF 2001). The recent war was also accompanied with displacement of nearly one-third of the total population and military mobilization of most young adults (mostly males, aged 18-40 years). With most of the young and productive population mobilized for military service, the burden of family responsibilities is on women and children. The border conflict coupled with political unrest has affected Ethiopia's economy as well. For instance, inflation stood at $15 \%$ in 2002-2003, although it declined to 7\% in 2004-2005. Economic growth has been fairly high but unstable; and annual real GDP growth rate averaged at about 5\% over the period 1999 to 2004 (CSA and ORC Macro 2006). There has also been and still is civil strife and political instability in Ethiopia which is likely to have had an impact on the socio-economic development of the country. It is likely that such hostilities and economic and political upheavals also have impacts on women's status and wellbeing in both countries.

Even though women in sub-Saharan African countries are often perceived to exercise little or no control over resources and to have little say on reproductive decisions (Makinwa and Jensen 1995), this should not be over-generalized since the amount of control men have over their wives and the disparity between men and women vary from place to place, change over time, and are influenced by several factors. In Eritrea, for instance, during the struggle for independence, women fighters were allowed to participate fully and equally in all aspects of activities of the Eritrean Peoples Liberation Front, EPLF (now the government of Eritrea). They have enjoyed some autonomy in participating in administration, decision-making and other nontraditional activities. Although the number of women in the EPLF was small, it is likely that participation of women during the war could have had some influence on the role of women in general, after independence. This was not, however, the case in Ethiopia, as the Ethiopian government recruited only men as soldiers to fight the EPLF. Further, the mobilization of young adults (mostly men), particularly in Eritrea, for the most recent war efforts might have rendered inadequate the ability of men to take care of household needs, which may facilitate the emergence of a new perception of the roles and rights of their wives. When married women are main supporters of the family and responsible for all activities of the household they are likely to gain more access and control over resources than in other situations. But, it is also likely that women's access to resources (health, education, and other social services) might have 
been negatively affected as resources of the country were diverted instead to defense purposes.

\section{The concept of women's autonomy}

Although women's autonomy is widely referred to in many studies, notably on reproductive status and health, the concept remains ill-defined and its relationship to demographic processes has not been well articulated, either theoretically or empirically (Presser and Sen 2000). There is no single accepted definition that represents it or that captures the multiple dimensions of women's position (Mason 1995). Alternative terms such as women's status, female position or role, closer ties to natal kin, control over resources, and prestige are all frequently used in the literature interchangeably to define women's status (Mason 1986; Bloom et al. 2001). Balk (1994) argues that women's status or autonomy can not be represented by one direct measure nor by one indirect proxy alone, and that different aspects of women's autonomy influence fertility differently, in terms of magnitude and direction. In most studies autonomy has been defined as the capacity to manipulate one's personal environment through control over resources and information in order to make decisions about one's own concerns or about close family members (Basu 1992, Dyson and Moore 1983). This involves an individual's capacity and freedom to act independently of the authority of others, for instance the ability to leave the house without asking anyone's permission, make personal decisions regarding contraceptive use or obtaining health care. Thus, women's autonomy can be conceptualized as the ability to make and execute independent decisions pertaining to personal matters of importance to their lives or their family, even though men and other people may be opposed to their wishes (Mason 1995). For the purpose of this study, we use the term autonomy as defined by the above authors and it is represented by some selected direct measures of women's autonomy, namely freedom of movement to visit families or relatives, decision-making power on making large household and daily purchases, and women's attitude toward domestic violence (i.e., wife beating).

\section{Data and methods}

The data for our study are from the Demographic and Health Surveys (DHS) conducted in Eritrea and Ethiopia in 2002 and 2005, respectively. The Eritrean survey, which is the second national representative and comprehensive survey of that 
country was conducted by the National Statistics and Evaluation Office (NSEO) under the auspices of the International Comparative Program of the Demographic and Health Surveys of ORC Macro in Maryland, U.S.A. A sample of 8,754 women of reproductive age (15-49 years) was interviewed in the survey, of which 5,730 are currently married (NSEO and ORC Macro 2003). The Ethiopian survey is the second comprehensive survey conducted by the Central Statistical Agency (CSA) of Ethiopia as part of the worldwide Demographic and Health Surveys project. It was a nationally representative sample survey of 14,070 women aged 15-49, of which 9,060 were currently married (CSA and ORC Macro 2006). Our analyses focus on last births of married women that occurred in the five years prior to the surveys. DHS surveys collect information on antenatal care for women who have given their last birth within five years preceding the survey date.

Logistic regression models were first fitted to investigate factors predicting the likelihood of involvement of women in decision-making on making large and daily household purchases, and on visiting relatives or families. We subsequently, fitted two logistic regression models for each of the outcome variables of our study to investigate the effect of women's autonomy on maternal health care seeking behaviour. The first of these latter models includes women's autonomy indicators only, while the second model adds the socio-economic indicators.

\section{Description of variables used in multivariate analyses of health-care seeking behaviour}

\section{Dependent variables}

Three dependent variables are used to investigate the relationship between women's autonomy and the use of maternal health care for the most recent recorded birth occurring to respondents of the two DHS surveys. These include:

1) antenatal care during pregnancy as measured by the frequency of visits,

2) delivery care, and

3) child immunization status. 
Antenatal care seeking behaviour is measured by whether the mother visited medical facility at least four times (recommended number of visits) during pregnancy of her last child. We also used a binary variable to model delivery care, reflecting whether the last child was born at a medical facility (hospital or clinic) versus at home, regardless of the type of attendant (health professional or other person). To model immunization status of the last child, we used a binary variable reflecting whether the child has received all the necessary vaccinations (full immunization) or not. A child is considered to be fully vaccinated if it has received a dose of BCG vaccine (against tuberculosis), three doses of DPT (a vaccine to immunize against diphtheria, pertussis and tetanus) three doses of polio immunization, and a measles vaccination by 12 months of age (NSEO and ORC Macro Inc.2003).

\section{Key explanatory variables}

The two groups of explanatory variables key to our study are the direct measures of women's autonomy and the traditional socio-economic indicators of women's status. The variables in each group are described below.

\section{Women's autonomy indicators}

The degree of women's autonomy is assessed in four different areas: women's decision-making power in making large household and daily purchases, extent of freedom of movement (via decisions on visiting families or relatives), and women's attitude toward partner's violence (via opinion toward wife beating). The selection of these autonomy variables is based on the review of literature and on the structure and limitation of the DHS data used.

Decisions about the two different kinds of purchases (i.e., large and daily ones) were meant to tap into economic decision-making in the household, while allowing for variation in participation according to the relative amount of money to be expended and according to whether the decisions are routine or not. Participation in decisions about visits to families, relatives or friends was expected to enhance women's ability to seek and gain knowledge which may influence their own and children's health and well-being. Women whose movement is restricted and where their interaction with relatives or friends is closely monitored by husbands and in-laws are expected to be 
less knowledgeable about health utilization than other women who have more freedom of movement.

In order to obtain information on the above measures of women's autonomy, the DHS surveys asked the following questions: "Who in your family usually has the final say on the following decisions":

Making large household purchases?

Making household purchases for daily needs?

Visits to family or relatives?

Responses are coded as 1) respondent, 2) respondent and husband/partner jointly, 3) respondent and someone else, 4) husband/partner, and 5) someone else in the household. To gain larger data in each category, responses 2 and 3, and 4 and 5 were merged so that three categories of each variable are created: Respondent alone, respondent and husband/others jointly, and husband/others.

In addition to aspects decision-making autonomy, indicated above, the DHS surveys contain questions related to gender-role norms that justify men's control over women. Of particular relevance to health programs and to our study is the following question: "In your opinion, is a husband justified in hitting or beating his wife in the following situations":

If she goes out without informing him?

If she argues with him?

If she neglects the children?

If she refuses to have sex with him?

If she burns the food?

These are general attitude questions, rather than questions that ask women about their own experience. The assumption with these questions is that women with high autonomy would not accept such obvious gender inequalities in power and would not agree with any justification for a husband beating his wife. For example, they would believe that a wife should have the right to decide when and whether she wants to have sex with her husband, or she argues with him. We define a variable with two categories from these questions to separate between respondents who feel wife beating is not justifiable for any of the reasons and respondents who feel wife beating is justifiable for any single or several reasons. 


\section{Socio-economic status (indirect indicators of women's status)}

Our socio-economic status indicators include women's and husband's education, women's current work and rural-urban residence. Education is measured in terms of the highest level of education attained. Three categories have been defined: no education, primary, and secondary or higher education. This categorization applies to both mother's and husband's education. Current work status of a woman is measured by whether the woman is currently working or not at the time of the interview. Residence refers to whether the respondent was living in rural or urban areas at the time of the survey.

\section{Autonomy characteristics of women in Eritrea and Ethiopia}

Figure 1 shows the percentage distribution of women's autonomy in household decision-making in Eritrea and Ethiopia and their attitudes towards partner's violence. The data in this figure are based on currently married women aged 15-49 years at the time of the interview of the 2002 Eritrea and 2005 Ethiopia DHS surveys. Overall, the results indicate that women's autonomy in most domains are quite similar in the two countries. Even though women's sole final say over large purchases and visiting relatives or friends are slightly higher in Eritrea than in Ethiopia, these differences disappear when women who are not currently living with their husbands (due to mobilization for military service) are excluded from the analysis (not presented here). In Ethiopia, the decisions concerning large household purchases and visiting families or relatives are primarily made jointly. In terms of women's attitudes towards wife beating, 83\% of women in Ethiopia and 73\% in Eritrea believe that wife beating is justified in at least one of the five domains indicated in the previous section. 


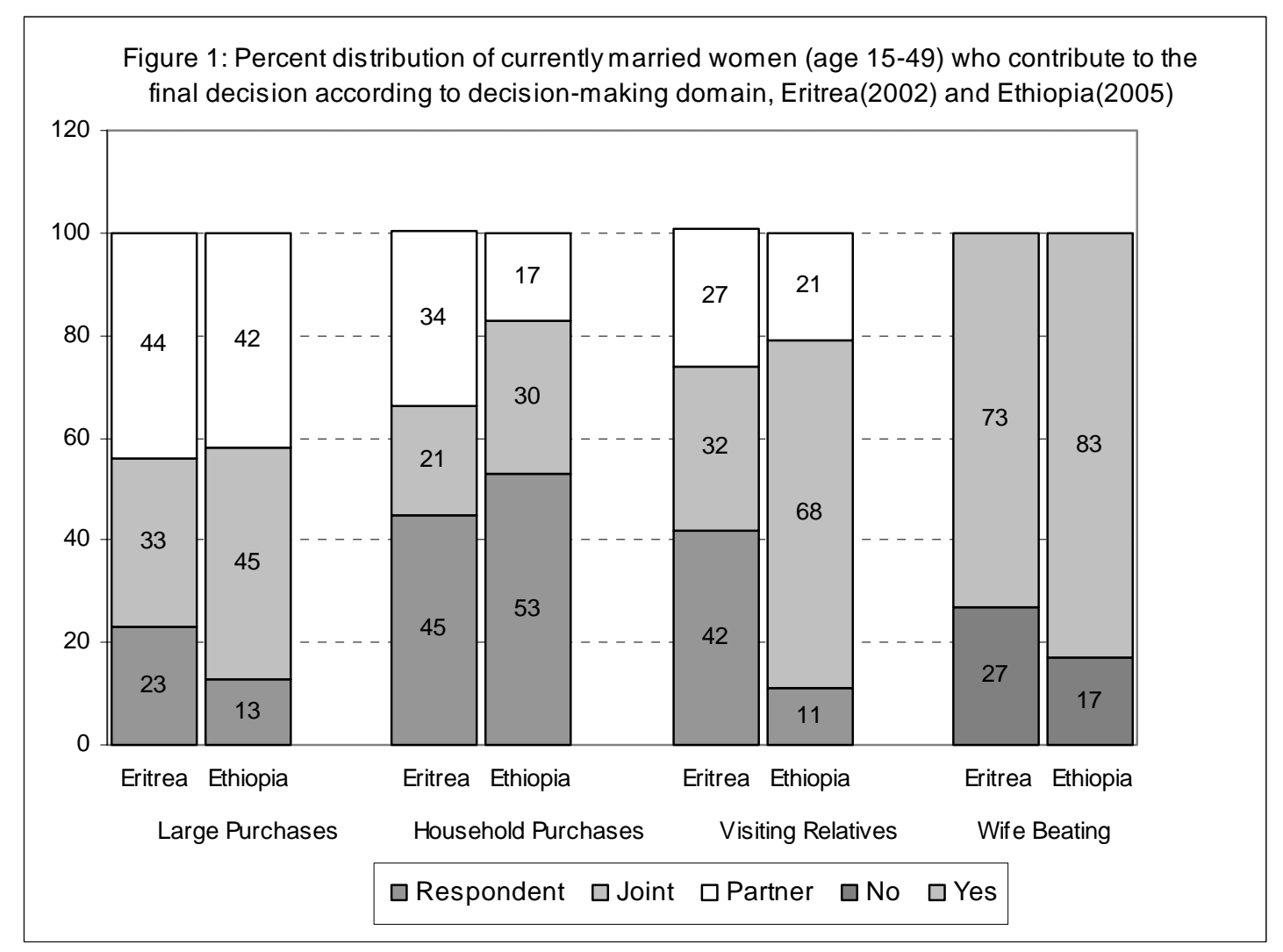

\section{Results}

\section{Determinants of women's autonomy}

Before we examine the link between autonomy and utilization of maternal health care, it is instructive to look first at the relationship between socio-economic characteristics and women's autonomy. Table 1 presents the results of the regression models estimated to examine this relationship in the two countries. In general, the socioeconomic indicators, as measured by women's and husband's education, women's current work (employment), and rural-urban residence appear to be important determinants of women's autonomy in both countries, though the importance of some of them varies by country.

Maternal education is positively associated with all dimensions of women's autonomy, but did not reach statistical significance for that of making large household purchases in Eritrea. In Ethiopia, maternal education has a strong positive relationship with all dimensions of women's decision-making domains, where women with higher education are more likely to be involved in decisions on making large and daily household purchases and visiting relatives or friends. In addition, higher level of 
husband's education significantly improves women's participation in all domains of women's autonomy in both countries, except in large purchases in Ethiopia. Further, factors that emerged as significant predictors of women's autonomy in both countries are current employment of women and place of residence. Currently working women are more likely to be positively associated with a greater involvement in all dimensions of autonomy in both countries. Women who live in urban areas are also found to be more autonomous than their rural counterparts. 
Table 1: Determinants of women’s autonomy in three different dimensions (odds ratios from logistic regression models), Eritrea 2002 and Ethiopia 2005

\begin{tabular}{|c|c|c|c|c|c|c|}
\hline \multirow{3}{*}{$\begin{array}{l}\text { Socio-economic } \\
\text { Determinants }\end{array}$} & \multicolumn{3}{|c|}{ Eritrea } & \multicolumn{3}{|c|}{ Ethiopia } \\
\hline & \multicolumn{3}{|c|}{ Women involved in decisions to } & \multicolumn{3}{|c|}{ Women involved in decisions to } \\
\hline & Purchase large items & Purchase daily items & Visit families & Purchase large items & Purchase daily items & Visit families \\
\hline \multicolumn{7}{|c|}{ Maternal education } \\
\hline No education & 1 & 1 & 1 & 1 & 1 & 1 \\
\hline Primary & 1.06 & $2.30 * * *$ & $1.81 * * *$ & $1.13^{*}$ & 1.07 & 1.01 \\
\hline Secondary+ & 1.20 & $2.35 * * *$ & $1.69 * * *$ & $2.43 * * *$ & $2.21 * * *$ & $2.26 * * *$ \\
\hline \multicolumn{7}{|c|}{ Husband's education } \\
\hline No education & 1 & 1 & 1 & 1 & 1 & 1 \\
\hline Primary & $1.84 * * *$ & $1.25^{* *}$ & $1.16^{*}$ & 0.94 & $1.25 * * *$ & 1.05 \\
\hline Secondary+ & $1.70 * * *$ & $1.35 * *$ & $1.63 * * *$ & 1.04 & $1.33^{* *}$ & $1.35 * * *$ \\
\hline \multicolumn{7}{|c|}{ Currently working } \\
\hline No & 1 & 1 & 1 & 1 & 1 & 1 \\
\hline Yes & $2.11 * * *$ & $2.52 * * *$ & $1.66 * * *$ & $1.37 * * *$ & $1.76^{* * *}$ & $1.58 * * *$ \\
\hline \multicolumn{7}{|c|}{ Place of residence } \\
\hline Urban & 1 & 1 & 1 & 1 & 1 & 1 \\
\hline Rural & $0.70 * * *$ & $0.59 * * *$ & $0.72 * * *$ & $0.48 * * *$ & $0.45 * * *$ & $0.54 * * *$ \\
\hline
\end{tabular}




\section{Relationship between women's autonomy and maternal health-care seeking behaviour}

The analysis in this section focuses on a set of outcome measures that contribute to both maternal and child health: utilization of antenatal care during pregnancy, delivery care at childbirth, and immunization after birth, all referring to the last child born five years preceding the surveys. Tables 2 through 4 show the results of multivariate logistic regressions with each of the three health care measures as outcomes and with women's autonomy indices and socio-economic indicators as independent variables for each country. Two separate models were run for each of the outcome measures. The first model in each table shows the effect of women's autonomy variables on the health outcomes, while the full model adds the socioeconomic background variables of women to examine whether the effects of the autonomy variables are influenced by the socio-economic variables or they are independent from such influences.

\section{Women's autonomy and antenatal care}

From the first models in Table 2, it is evident that women's sole final say on all the autonomy indices, except on purchasing large household items in Eritrea, have a strong positive association with the level of antenatal care obtained. More specifically, women who can make the final decision alone in making day-to-day household purchases, visiting families or friends and those who disagree with wife beating are more likely to have received antenatal care in their last pregnancy than women who do not have a final say (Model 1, Table 2). In the full model (Model 2), while women's sole final say on visiting families or friends in both countries and on daily household purchases in Eritrea still demonstrates a strong and positive association with use of antenatal care when controlling for the socio-economic variables, the opposite appears to be the case for women's final say on making large household purchases. Disagreement with wife beating in Ethiopia also retained its significant positive effect on utilization of antenatal care after the socio-economic variables are held constant. Urban residence and high maternal and husband's education all have a positive relationship to antenatal care utilization in both countries. Women's current work has a positive association with antenatal care in Ethiopia, but not in Eritrea. 
Table 2: Determinants of antenatal care utilization (four or more antenatal care visits in last pregnancy),

Eritrea 2002 and Ethiopia 2005

\begin{tabular}{|c|c|c|c|c|}
\hline \multirow[b]{2}{*}{ Determinants } & \multicolumn{2}{|c|}{ Eritrea } & \multicolumn{2}{|c|}{ Ethiopia } \\
\hline & $\begin{array}{l}\text { Model with } \\
\text { autonomy only } \\
\text { (Model 1) }\end{array}$ & $\begin{array}{l}\text { Full } \\
\text { model } \\
\text { (Model 2) }\end{array}$ & $\begin{array}{l}\text { Model with } \\
\text { autonomy only } \\
\text { (Model 1) }\end{array}$ & $\begin{array}{l}\text { Full } \\
\text { model } \\
\text { (Model 2) }\end{array}$ \\
\hline \multicolumn{5}{|c|}{ AUTONOMY INDICATORS } \\
\hline \multicolumn{5}{|c|}{ Decision on purchasing large items } \\
\hline Respondent alone & 1 & 1 & 1 & 1 \\
\hline Jointly & $1.59 * * *$ & $1.43^{* * *}$ & 1.08 & $1.49 * * *$ \\
\hline Partner or others & 1.12 & 1.18 & $0.71 * * *$ & $1.51 * * *$ \\
\hline \multicolumn{5}{|c|}{ Decision on purchasing daily items } \\
\hline Respondent alone & 1 & 1 & 1 & 1 \\
\hline Jointly & $0.49 * * *$ & $0.69 * * *$ & $0.63 * * *$ & 0.99 \\
\hline Partner or others & $0.48 * * *$ & 0.84 & $0.68 * * *$ & 0.88 \\
\hline \multicolumn{5}{|c|}{ Decision on visiting families/relatives } \\
\hline Respondent alone & 1 & 1 & 1 & 1 \\
\hline Jointly & 0.92 & 0.86 & 0.87 & $0.72 * *$ \\
\hline Partner or others & $0.79 * *$ & $0.72 * *$ & $0.49 * * *$ & $0.56 * * *$ \\
\hline \multicolumn{5}{|c|}{ Wife beating justified } \\
\hline Yes & 1 & 1 & 1 & 1 \\
\hline No & $1.38 * * *$ & 0.95 & $3.02 * * *$ & $1.60 * * *$ \\
\hline \multicolumn{5}{|c|}{ SOCIO-ECONOMIC INDICATORS } \\
\hline \multicolumn{5}{|c|}{ Maternal education } \\
\hline No education & - & 1 & - & 1 \\
\hline Primary & - & $2.20 * * *$ & - & $1.70 * * *$ \\
\hline Secondary+ & - & $4.55 * * *$ & - & $3.45 * * *$ \\
\hline \multicolumn{5}{|c|}{ Husband's education } \\
\hline No education & - & 1 & - & 1 \\
\hline Primary & - & $1.62 * * *$ & - & $1.64 * * *$ \\
\hline Secondary+ & - & $1.67 * * *$ & - & $2.79 * * *$ \\
\hline \multicolumn{5}{|c|}{ Currently working } \\
\hline No & - & 1 & - & 1 \\
\hline Yes & - & 0.93 & - & $1.28^{* *}$ \\
\hline \multicolumn{5}{|l|}{ Place of residence } \\
\hline Urban & - & 1 & - & 1 \\
\hline Rural & - & $0.20 * * *$ & - & $0.15^{* * *}$ \\
\hline
\end{tabular}




\section{Women's autonomy and place of delivery}

We obtained almost similar results of the autonomy indices as in the previous section for our analyses pertaining to care at delivery when we do not control for the socioeconomic variables (Model 1, Table 3), but we obtain much less effect when those later variables are held constant (Model 2). In the uncontrolled models (Model 1) which contain only the four indices of women's autonomy, women's final say (either jointly or alone) in all autonomy indices, except in visiting families or friends in Eritrea show a significant positive association with the likelihood of having used a health facility at the birth of the last child. In the full model, practically all indices except that of disagreement with wife beating in Ethiopia have lost their significant effects on using safe delivery care. The full model also shows that both wife's and husband's education and women's current employment are associated positively and significantly with the likelihood of safe delivery care. Urban women are also significantly more likely to use safe delivery care than rural women.

\section{Women's autonomy and immunization status of last child}

Table 4 presents the odds ratios from the logistic regression models, in which the dichotomy of whether the child has received all the necessary immunizations versus not received all immunizations is the dependent variable. In the first model, women's final say in most of the autonomy indices is positively associated with seeking child immunization. Children of women who have the final say (either alone or jointly with partner/others) in decisions on day-to-day household purchases and of visiting relatives or families in both countries and who disagrees wife beating in Ethiopia are more likely to receive all the necessary vaccinations. In the full model, only decisions on visiting families or friends still retained its significance in Eritrea. In Ethiopia, the effects of decisions on daily purchases and visiting relatives largely remained intact when controlling for the socio-economic variables while the effect of attitude on wife beating disappears when the variables are held constant.

Regarding the socio-economic indicators, except for current work status in Eritrea, all are positively and significantly associated with child immunization. That is, the likelihood that the last child is getting the full regimen of immunization is significantly higher in households where women and husbands have some education, women are currently working, and if the family is residing in an urban area. 
Table 3: Determinants of delivery care utilization (last-born child was delivered in medical facility),

Eritrea 2002 and Ethiopia 2005

\begin{tabular}{|c|c|c|c|c|}
\hline \multirow[b]{2}{*}{ Determinants } & \multicolumn{2}{|c|}{ Eritrea } & \multicolumn{2}{|c|}{ Ethiopia } \\
\hline & $\begin{array}{l}\text { Model with } \\
\text { autonomy only } \\
\text { (Model 1) }\end{array}$ & $\begin{array}{l}\text { Full } \\
\text { model } \\
\text { (Model 2) } \\
\end{array}$ & $\begin{array}{l}\text { Model with } \\
\text { autonomy only } \\
\text { (Model 1) }\end{array}$ & $\begin{array}{l}\text { Full } \\
\text { model } \\
\text { (Model 2) } \\
\end{array}$ \\
\hline \multicolumn{5}{|c|}{ AUTONOMY INDICATORS } \\
\hline \multicolumn{5}{|c|}{ Decision on purchasing large items } \\
\hline Respondent alone & 1 & 1 & 1 & 1 \\
\hline Jointly & $1.58 * * *$ & $1.41^{* *}$ & $0.79 * *$ & 0.94 \\
\hline Partner or others & 1.00 & 1.07 & $0.43 * * *$ & 0.83 \\
\hline \multicolumn{5}{|c|}{ Decision on purchasing daily items } \\
\hline Respondent alone & 1 & 1 & 1 & 1 \\
\hline Jointly & $0.51 * * *$ & 0.91 & $0.57 * * *$ & 0.96 \\
\hline Partner or others & $0.52 * * *$ & 1.22 & $0.80 *$ & 1.26 \\
\hline \multicolumn{5}{|c|}{ Decision on visiting families/relatives } \\
\hline Respondent alone & 1 & 1 & 1 & 1 \\
\hline Jointly & 0.94 & 0.85 & 1.13 & 0.99 \\
\hline Partner or others & 0.92 & 0.83 & $0.60 * * *$ & 0.80 \\
\hline \multicolumn{5}{|c|}{ Wife beating justified } \\
\hline Yes & 1 & 1 & 1 & 1 \\
\hline No & $1.63 * * *$ & 0.97 & $3.42 * * *$ & $1.65 * * *$ \\
\hline \multicolumn{5}{|c|}{ SOCIO-ECONOMIC INDICATORS } \\
\hline \multicolumn{5}{|c|}{ Maternal education } \\
\hline No education & - & 1 & - & 1 \\
\hline Primary & - & $2.03 * * *$ & - & $1.56 * * *$ \\
\hline Secondary+ & - & $5.97 * * *$ & - & $3.14 * * *$ \\
\hline \multicolumn{5}{|c|}{ Husband's education } \\
\hline No education & - & 1 & - & 1 \\
\hline Primary & - & $1.42 * * *$ & - & $1.47 * * *$ \\
\hline Secondary+ & - & $2.96 * * *$ & - & $3.11^{* * *}$ \\
\hline \multicolumn{5}{|c|}{ Currently working } \\
\hline No & - & 1 & - & 1 \\
\hline Yes & - & $1.33^{* *}$ & - & $1.46 * * *$ \\
\hline \multicolumn{5}{|l|}{ Place of residence } \\
\hline Urban & - & 1 & - & 1 \\
\hline Rural & - & $0.13^{* * *}$ & - & $0.11^{* * *}$ \\
\hline
\end{tabular}


Table 4: Determinants of child immunization (last child received all the necessary vaccines), Eritrea 2002 and Ethiopia 2005

\begin{tabular}{|c|c|c|c|c|}
\hline \multirow[b]{2}{*}{ Determinants } & \multicolumn{2}{|c|}{ Eritrea } & \multicolumn{2}{|c|}{ Ethiopia } \\
\hline & $\begin{array}{l}\text { Model with } \\
\text { autonomy only } \\
\text { (Model 1) }\end{array}$ & $\begin{array}{l}\text { Full } \\
\text { model } \\
(\text { Model 2) } \\
\end{array}$ & $\begin{array}{l}\text { Model with } \\
\text { autonomy only } \\
\text { (Model 1) }\end{array}$ & $\begin{array}{l}\text { Full } \\
\text { model } \\
\text { (Model 2) } \\
\end{array}$ \\
\hline \multicolumn{5}{|c|}{ AUTONOMY INDICATORS } \\
\hline \multicolumn{5}{|c|}{ Decision on purchasing large items } \\
\hline Respondent alone & 1 & 1 & 1 & 1 \\
\hline Jointly & 1.25 & 1.08 & $1.40 * *$ & $1.67 * * *$ \\
\hline Partner or others & 0.90 & 0.86 & 0.88 & $1.42 * * *$ \\
\hline \multicolumn{5}{|c|}{ Decision on purchasing daily items } \\
\hline Respondent alone & 1 & 1 & 1 & 1 \\
\hline Jointly & $0.74 *$ & 1.10 & $0.70 * * *$ & 0.97 \\
\hline Partner or others & $0.61 * * *$ & 1.05 & $0.63 * * *$ & $0.73^{* *}$ \\
\hline \multicolumn{5}{|c|}{ Decision on visiting families/relatives } \\
\hline Respondent alone & 1 & 1 & 1 & 1 \\
\hline Jointly & 0.80 & $0.75^{*}$ & 1.08 & 1.09 \\
\hline Partner or others & $0.58 * * *$ & $0.55 * * *$ & $0.52 * * *$ & $0.62 * *$ \\
\hline \multicolumn{5}{|c|}{ Wife beating justified } \\
\hline Yes & 1 & 1 & 1 & 1 \\
\hline No & 1.02 & 0.84 & $2.15 * * *$ & 1.12 \\
\hline \multicolumn{5}{|c|}{ SOCIO-ECONOMIC INDICATORS } \\
\hline \multicolumn{5}{|c|}{ Maternal education } \\
\hline No education & - & 1 & - & 1 \\
\hline Primary & - & $1.56 * *$ & - & $1.86 * * *$ \\
\hline Secondary+ & - & $1.48^{* *}$ & - & $2.85 * * *$ \\
\hline \multicolumn{5}{|c|}{ Husband's education } \\
\hline No education & - & 1 & - & 1 \\
\hline Primary & - & $1.37 * *$ & - & $1.49 * * *$ \\
\hline Secondary+ & - & $1.88 * * *$ & - & $1.72 * * *$ \\
\hline \multicolumn{5}{|c|}{ Currently working } \\
\hline No & - & 1 & - & 1 \\
\hline Yes & - & 0.83 & - & $2.10 * * *$ \\
\hline \multicolumn{5}{|l|}{ Place of residence } \\
\hline Urban & - & 1 & - & 1 \\
\hline Rural & - & $0.17 * * *$ & - & $0.20 * * *$ \\
\hline
\end{tabular}

\section{Conclusion}

In this study, women's autonomy, as measured by the extent of women's sole final say in decisions on making large and daily household purchases and of visiting families or relatives as well as women's attitude toward wife beating and their association with maternal health care utilization are examined using data from the DHS surveys of Eritrea and Ethiopia. The primary aim is to determine whether there is a link between women's autonomy and utilization of maternal and child health care in these countries and if so how such relationships depend on socio-economic factors such as educational attainment of women and husband, women's current work status, and place of residence. 
After describing the concept of autonomy and each of the autonomy indices indicated above, we explored the evidence regarding the level of women's autonomy in the two countries. We then looked at the relationship between socio-economic characteristics and autonomy indices of women. Finally, we examined our hypothesis on whether women's autonomy increases maternal care seeking behaviour.

The findings indicate that the levels of women's decision-making autonomy are generally low in both countries and no important difference is observed between the two countries. More than four-fifths of women in Ethiopia and close to three-fourths of women in Eritrea believe that wife beating is justified for some or all of the reasons indicated in the women's autonomy indicators section. This demonstrates how widely accepted wife beating is in the two countries and underlines the strength of gender discrimination and women's subordination to men. As in many other societies in Africa (Makinwa and Jensen 1995), women's worth is measured in terms of her role as a mother and wife, especially in the rural areas of Ethiopia and Eritrea. Although women have made substantial contributions both as fighters and as civilian to the struggle Ethiopian and Eritrean people have waged to ensure their rights and freedoms during the 1980s, their position up to now has not been sufficiently institutionalized. For instance in Eritrea, women who joined the struggle for independence participated in activities of the Eritrean Front and made some gains in political decision-making powers. However, after independence, such participation appears to have had little impact on the role of women in household and society. Particularly, in rural areas, this did not change their subordinate status, which is based on deep-rooted values and believes. As a result there has been relatively little improvement in the status and lives of women in the two countries. In addition, in the past ten years these countries have experienced a devastating military conflict between each other. Thus, given the various, social, economic and cultural problems in these countries, the observed low levels of women's autonomy in decision-making and their support for partner's violence is not all surprising.

The results of our study show that most of our specified socio-economic factors have significant influence on women's autonomy, with women's current employment and rural-urban residence being the most important predictors for each dimension of autonomy. These findings are consistent with those of recent studies focusing on the 
influence of women's socio-economic status on autonomy outcomes in Latin America (Healton et al. 2005).

The most important result from our analyses on health-seeking behaviour during pregnancy, childbirth, and child immunization is that several socio-economic characteristics, particularly women's and husband's education and place of residence have strong positive association with health-care utilization, implying that these variables have direct effects on the use of health care facilities. On the other hand, the results suggest that not all dimensions of women's autonomy are important predictors of these health outcomes. The effects of women's autonomy varied by the health outcomes and country and some of them lost their significance after the socioeconomic indicators are controlled. For instance, women's sole final say in decisions on visiting families or friends increases health-care utilization during antenatal care and child immunization in both countries, but not at childbirth. Women who have sole finale decisions on making day-to-day purchases are more likely to seek antenatal care during pregnancy in Eritrea and child immunization in Ethiopia than other women. The effect of attitude on wife beating is statistically significant, but in most cases, the statistical significance is attenuated or becomes weaker when the socioeconomic indicators are controlled.

The most relevant conclusion from this study is that in countries like Ethiopia and Eritrea where women's autonomy is low, health-care seeking behaviours are more strongly affected by socio-economic factors - like education, residence and employment. But, the effects of some of women's direct autonomy indices like decisions on visiting relatives or friends and on day-to-day purchases which retained their significant effects after controlling for the socio-economic factors should not be ignored in studies like the one we have carried out.

Overall, an analysis that integrates both the socio-economic factors and women's autonomy is the most appropriate in a study on maternal and child health care utilization than one that includes only the socio-economic or autonomy indices. For instance, if geographical distance is an issue, which is often the case with maternity hospitals in Eritrea and Ethiopia, then financial constraints and lack of awareness on health care utilization can still be barriers to uptake the services. Transportation costs 
or lack of information can be problems in access to maternal care (Okojie 1994). On the other hand, even if a woman has adequate financial resources and/or education, her low level of autonomy due to lack of authority and restriction by her husband can lead to low uptake of maternal health services. In this case, as a result of the compromised decision-making autonomy, maternal care seeking behaviour could be negatively affected. Finally, our results may be tentatively only because they are based on cross-sectional survey data with imperfect measures and definitions of women's autonomy. Attention needs to be given to developing better measures of women's autonomy at the household level and using those refined measures to study maternal and child health outcomes and care seeking behaviour. The measures of autonomy used in our analysis could be improved by incorporating information on other issues, such as whether a woman can use resources of the household for obtaining health care for her own and her children without any permission of the husband, or whether she can stay with her relatives or families for a week or more without her husband's permission in case the timing of her stay matters more than simply asking whether she can visit at all.

\section{Acknowledgement}

This paper was made while I was a research fellow at the Max Planck Institute for Demographic Research in Rostock, Germany and at the Demography Unit/Sociology Department, Stockholm University. I gratefully acknowledge the support of Prof. Jan Hoem at the Max Planck Institute in Germany and the Swedish Council for Working Life and Social Research (or FAS) in Stockholm, Sweden. I would also like to extend my appreciation to Dr Gunnar Andersson for comments and editorial advice on this manuscript. 


\section{References}

Amin S. and Lloyd C.B. 1997. The gender dynamics of recent rapid transitions: The case of Bangladesh and Egypt. A paper presented in the seminar on female empowerment and demographic processes: Moving beyond Cairo. 21-24 April 1997, Lund, Sweden.

Balk D. 1994. Individual and community aspects of women's status and fertility in rural Bangladesh. Population Studies, 48(1): 21-45.

Basu A.M. 1993. Culture, the Status of Women and Demographic Behaviour Illustrated with the Case of India. Oxford: Clarendon Press.

Becker S. 1997. Incorporating women's empowerment in studies of reproductive health: an example from Zimbabwe. Paper presented in the seminar on female empowerment and demographic processes: Moving beyond Cairo. 21-24 April 1997, Lund, Sweden.

Bhatia J. and Cleland J. 1995b. Self-reported symptoms of gynaecological morbidity and their treatment in south India. Studies in Family Planning, 26(4): 203-216.

Bloom S.S., Wypij D. and Das Gupta M. 2001. Dimensions of women's autonomy and the influence on maternal health care utilization in a north Indian city. Demography 28(1): 67-78.

CSA (Central Statistical Agency)[Ethiopia] and ORC Macro 2006. Ethiopia Demographic and Health Survey 2005. Addis Ababa, Ethiopia and Calverton, Maryland, USA:

Desai S. and Johnson K. 2005. Women's decision-making and child health: Familial and social hierarchies, In Kishor S. (ed.) 2005. A Focus on Gender: Collected Papers on Gender using DHS data. Calverton, Maryland, USA: ORC Macro.

Dharmalingam A. and Morgan S.P. 1996. Women's work, autonomy and birth control: Evidence from two south Indian villages. Population Studies, 50(2): 187201.

Dyson T. and Moore T. 1983. On kinship structure, female autonomy, and demographic behaviour in India. Population and Development Review, 9(1): 35-54.

GSE (The Government of the State of Eritrea) and UNICEF 2001. Towards Realizating Child Rights in Eritrea: An Analysis of the Situation of Children and Women, Asmara.

Healton T., Huntsman T.J. and Flake D. F. 2005. The effects of status on women's autonomy in Bolivia, Peru and Nicaragua. Population Research and Policy Review, 24: 283-300. 
Hindin M. 2005. Women's autonomy, status, and nutrition in Zimbabwe, Zambia, and Malawi. In Kishor S. (ed.) A Focus on Gender: Collected Papers on Gender using DHS Data. Calverton, Maryland, USA: ORC Macro.

http://en.wikedia.org/wiki/Ethiopia: Ethiopia-wikipedia, the free Encyclopaedia.

IUSSP 1997. Report of Seminar on Female Empowerment and Demographic Processes: Moving Beyond Cairo. 21-24 April 1997, Lund, Sweden.

Jejeebhoy S.J. 1995. Women's Education, Autonomy and Reproductive Behaviour: Experience from Developing Countries, Clarendon Press, Oxford

Jejeebhoy S.J. 1991. Women's status and fertility: Successive cross-sectional evidence from Tamil Nadu, India. Studies in Family Planning, 22(4): 217-30.

Kishor S. 2000. Empowerment of women in Egypt and links to the survival and health of their infants. In Presser H. and Sen G. (eds.) Women's Empowerment and Demographic Processes: Moving Beyond Cairo. New York: Oxford University Press.

2005. A Focus on Gender: Collected Papers on Gender using DHS data. Calverton, Maryland, USA: ORC Macro.

Makinwa P. and Jensen A. (eds.) 1995. Women's Position and Demographic Change in sub-Saharan Africa. IUSSP, Liege, Belgique.

Morgan P. and Niraula 1995. Gender inequality and fertility in two Nepali villages. Population and Development Review, 21(3): 541-561.

Mason K.O. 1986. The status of women: conceptual and methodological issues in demographic studies. Sociological Forum, 1(2): 284-300.

1994. Conceptualizing and measuring women's status. Paper presented at the Annual Meeting of the Population Association of America. May 1994, Miami, Florida.

1995. Gender and Demographic Change: What do we Know? ISBN 287108-052-14. International Union for the Scientific Study of Population. Liege

NSEO (National Statistics and Evaluation Office) [Eritrea] and ORC Macro 2003. Eritrea Demographic and Health Survey 2002. Calverton, Maryland, USA.

Okojie C.E. 1994. Gender inequalities of health in the third world. Social Science and Medicine, 39(9): 1237-1247.

Presser H. and Sen G. 2000. Women's Empowerment and Demographic Processes: Moving Beyond Cairo. Oxford University Press. UK.

Population Reference Bureau (PRB) 2006. 2006 World population Data Sheet of the Population Reference Bureau. website: www.prb.org. 
Safilios-Ruthschild C. 1990. Women's income profile as a key indicator of women's status for the understanding of changing fertility behaviour in rural Kenya. Genus, 46 (3-4): 31-34.

Schuler S.R. and Hashemi S. 1994. Credit programs, women's empowerment, and contraceptive use in rural Bangladesh. Studies in Family Planning, 25(2): 65-76.

Tfaily R. 2004. Do women with higher autonomy have lower fertility? Evidence from Malaysia, the Philippines and Thailand. Genus. LXL(2): 7-32.

United Nations 1994. Summary Report of the Program of Action of the International Conference on Population and Development. New York: United Nations. 
Annex

Table 5: Percent of pregnancies/deliveries of last child and last live births that occurred within five years preceding the surveys according to health outcomes and autonomy and socio-economic indicators, Eritrea 2002 and Ethiopia 2005

\begin{tabular}{|c|c|c|c|c|c|c|}
\hline \multirow{2}{*}{ Indicators } & \multicolumn{3}{|c|}{ Eritrea } & \multicolumn{3}{|c|}{ Ethiopia } \\
\hline & Antenatal care & $\begin{array}{l}\text { Place of } \\
\text { delivery }\end{array}$ & Immunization & Antenatal care & Place of delivery & Immunization \\
\hline \multicolumn{7}{|c|}{ Autonomy Indicators } \\
\hline \multicolumn{7}{|c|}{$\begin{array}{l}\text { Decisions on purchasing large household } \\
\text { items }\end{array}$} \\
\hline Respondent alone & 21.5 & 21.5 & 21.3 & 15.5 & 15.5 & 17.1 \\
\hline Jointly & 32.3 & 32.3 & 32.5 & 41.5 & 41.5 & 38.6 \\
\hline Partner or others & 46.2 & 46.2 & 46.2 & 43.0 & 43.0 & 44.3 \\
\hline \multicolumn{7}{|c|}{$\begin{array}{l}\text { Decisions on purchasing daily household } \\
\text { items }\end{array}$} \\
\hline Respondent alone & 40.5 & 46.6 & 40.5 & 54.2 & 54.2 & 53.0 \\
\hline Jointly & 22.4 & 22.4 & 22.5 & 27.7 & 27.7 & 26.7 \\
\hline Partner or others & 37.1 & 37.0 & 37.0 & 18.1 & 18.1 & 20.3 \\
\hline \multicolumn{7}{|c|}{ Decisions on visiting families or relatives } \\
\hline Respondent alone & 38.9 & 38.8 & 39.6 & 11.1 & 11.1 & 11.0 \\
\hline Jointly & 32.1 & 32.2 & 32.1 & 66.4 & 66.4 & 65.0 \\
\hline Partner or others & 29.0 & 29.0 & 28.3 & 22.5 & 22.5 & 24.0 \\
\hline \multicolumn{7}{|c|}{ Wife beating justifiable } \\
\hline yes & 72.2 & 72.3 & 71.8 & 81.3 & 81.3 & 81.8 \\
\hline No & 27.8 & 27.7 & 28.2 & 18.7 & 18.7 & 18.2 \\
\hline \multicolumn{7}{|c|}{ Socio-economic Indicators } \\
\hline \multicolumn{7}{|c|}{ Maternal education } \\
\hline No education & 70.7 & 70.8 & 68.9 & 76.2 & 76.1 & 77.9 \\
\hline Primary & 20.5 & 20.4 & 21.8 & 15.7 & 15.6 & 14.2 \\
\hline Secondary+ & 8.8 & 8.8 & 9.3 & 8.1 & 8.3 & 7.9 \\
\hline \multicolumn{7}{|c|}{ Husband's education } \\
\hline No education & 58.9 & 58.9 & 57.8 & 58.2 & 58.2 & 61.4 \\
\hline
\end{tabular}




\begin{tabular}{|c|c|c|c|c|c|c|}
\hline Primary & 26.6 & 26.6 & 26.5 & 26.3 & 26.2 & 23.8 \\
\hline Secondary+ & 14.5 & 14.5 & 15.7 & 15.5 & 15.6 & 14.8 \\
\hline \multicolumn{7}{|c|}{ Currently working } \\
\hline No & 85.9 & 86.0 & 86.4 & 77.1 & 77.1 & 79.9 \\
\hline Yes & 14.1 & 14.0 & 13.6 & 22.9 & 22.9 & 20.1 \\
\hline \multicolumn{7}{|c|}{ Place of residence } \\
\hline Urban & 27.1 & 27.2 & 28.4 & 14.5 & 14.6 & 14.5 \\
\hline Rural & 72.9 & 72.8 & 71.6 & 85.5 & 85.4 & 85.5 \\
\hline Total & 3,857 & 3,868 & 2,405 & 5,861 & 5,897 & 3,036 \\
\hline
\end{tabular}

